\title{
Characterization of subsistence sheep farming: The case of three communities of the municipality of Tlahuapan, Puebla, Mexico
}

\author{
Galván-Antonio A. ${ }^{1}$, Sánchez-Hernández $\mathrm{M}^{1}{ }^{1}$, Calderón-Sánchez $\mathrm{F}^{1}{ }^{1}$, Guerrero-Rodríguez Juan de D. ${ }^{1 *}$ \\ ${ }^{1}$ Colegio de Postgraduados, Campus Puebla, México. \\ *Corresponding Author: rjuan@acolpos.mx
}

\begin{abstract}
Objective: to characterize household units for sheep production at three localities in the Santa Rita Tlahuapan municipality, Puebla.

Design/methodology/approach: semi-structured interviews conducted with 38 producers. Variables of the producer profile, crop production and herd management were analyzed using descriptive statistics, cluster analysis and variance analysis.

Results: four groups of producers were identified; most of them (92\%) were classified as small producers, with 24 to 36 sheep and low production of crop forage. The producer's average age was 55 years, with an average family size of four. Economic savings is the main objective for this production and family labor is used exclusively in sheep farming activities. The animals are housed in rustic pens, with no difference in their age, sex or physiological stage. Their main food source is pastures forage and cultivation areas; mostly supplemented (92\%) with mineral blocks and common salt.

Limitations/Implications: the lack of producer records and social mistrust to some degree to provide information.

Findings/conclusions: the assessed productive units are for subsistence, having sheep farming as a secondary activity, with low productive parameters. The poor housing practices, the scarcity of own grazing lands, and the animal's nutritional stress are identified as the main factors that stagnate sheep farming in the study area.
\end{abstract}

Keywords: sheep, subsistence producers, production systems, typology

\section{INTRODUCTION}

MPr sheep production makes marginal contributions to the global meat and milk

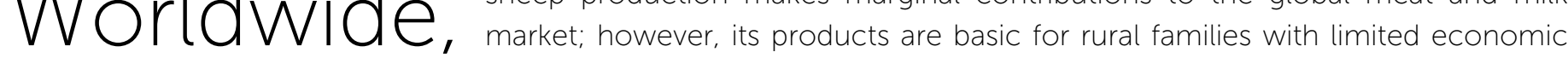
resources in various regions, mainly in developing countries (Alonso et al., 2010). In this regard, low purchasing power producers use sheep as a source for savings, income, and as a genetic resource inherent to family food security (Tesfay and Kumar, 2014). However, it is considered a secondary activity, since minimum inputs are invested, nor in their infrastructure and technology, which is why it is classified as a subsistence activity (Gizaw et al., 2010).

Agroproductividad: Vol. 13, Núm. 12, diciembre. 2020. pp: 39-44. Recibido: marzo, 2020. Aceptado: noviembre, 2020. 
Productivity, in most cases, is markedly low due to genetic, environmental, and institutional factors (Gizaw et al., 2010), with the main critical points being the scarcity of grazing land, poor nutrition and scarce suitable housing infrastructure (Legesse et al., 2008; Lakew et al., 2017). Due to poor management, animals are generally prone to infectious diseases, uncontrolled reproduction and conception rates, as well as the lamb's births set to non-strategic or forage-scarce seasons, resulting in high mortality.

According to Kechero et al. (2013), if the main critical points of subsistence sheep production are identified and characterized, it is possible to improve and increase the potential of the system. Examples from this in Africa (Legesse et al., 2008; Gizaw et al., 2010), have suggested selection criteria and genetic improvement strategies, local forage production, supplementation and veterinary medicine plans, practices that may result in positive changes in the herds.

In the temperate zones of Mexico, in the state of Puebla, at the municipality of Santa Rita Tlahuapan, sheep farming is a traditional and deeply rooted practice, of which very little has been documented about the identification, characterization and documentation of their production system. Therefore, for the region, critical points and management plans that could be established for production improvement to increase the economic income of the producers are unknown. Based on the above, the objective of this study was to describe the productive characteristics of sheep farming, its management practices, as well as to identify and prioritize the limitations that impact the development of production, to propose possible strategies and opportunities for herd improvement.

\section{MATERIALS AND METHODS}

Study area. The evaluation took place at the municipality of Santa Rita Tlahuapan, Puebla, Mexico (19 ${ }^{\circ} 15^{\prime} 36^{\prime \prime}$ and $19^{\circ} 27^{\prime} 54^{\prime \prime} \mathrm{LN}$ and $98^{\circ} 29^{\prime} 18^{\prime \prime}$ and $98^{\circ} 40^{\prime} 06^{\prime \prime}$ LW), 2,640 $\mathrm{m}$ altitude, with temperate and semi-cold subhumid climate.

The communities of La Preciosita, Santa Cruz Moxolahuac and San Juan Cuauhtémoc were selected for having a greater sheep number. The sampling frame was made through guided visits and participatory meetings with the producers, and a Neyman stratified random sample (Olayiwola et al., 2013) of 38 family units was obtained.
Sheep farming characterization. A questionnaire was applied with variables on the profile of the producer, agricultural resources availability, social and economic aspects, herd management and facilities, among others. Direct coproparasitoscopic tests were performed on 400 sheep ( $\geq 4$ months of age, indirectly estimated by the dentition, including all males and stallions). An eggs per gram counting from the feces was performed following the McMaster technique, using the total count per 100/number of chambers. These animals were also blood sampled to test for Brucella abortus using the card method (Official Mexican Standard NOM-041ZOO-1995).

Statistical analysis. According to the methodology described by Köbrich et al. (2010), the production units were characterized, and the producers were typified utilizing a cluster analysis. With the obtained data, an analysis of variance was conducted using the PROC GML procedure and a means comparison with the Tukey test with $\alpha=0.05$ in the SAS (2002) statistical software.

\section{RESULTS AND DISCUSSION}

Producers profile: Many producers (89.5\%) have agriculture as their main activity, 5.2\% stated to be merchants and $5.3 \%$ dedicated exclusively to livestock activities. The average number of members per family was four.

Agricultural crops: The main crops for family sustenance are corn, beans, oats, and wheat, produced during the rainy season. From the corn and beans, $70 \%$ of the production is used for self-sustenance and $30 \%$ for sale. As for oats and wheat, $65 \%$ is used for livestock fodder and $35 \%$ for sale. Land tenure for agricultural activities is mainly communal (84\%), the rest is private.

Sheep farming characteristics: The herds are mainly managed by men (84.9\%), women have little participation (10.6\%). The average time that a producer has dedicated himself to this activity is 19.5 years. In addition to sheep, there are also goats, poultry, horses, and donkeys to a lesser extent. The average size of the herds was 37 sheep mainly composed of "vientres" and "primalas". The breeds are mixed-race type, with some crosses with Suffolk-Dorper and Hamshire-Dorper breeds.

Animal nutrition: It is based on pasture grazing (44.7\%) and post-harvest agricultural areas (28.9\%) mainly, and some other crops such as wheat (13.1\%), barley (2.6\%), 
and alfalfa (7.8\%). Out of the crop residues, the most used is corn stubble, used all year round due to its high availability. The average time spent grazing is 3 hours with an interval of 2-4 hours. Of the producers, 92.1\% supplement the entire herd, some only the stallions (2.6\%) during the breeding season and others do not carry out this activity (5.3\%). The most common supplements are mineral building blocks, common salt, vitamins, and some forage grains.

Housing: The housing pens are mostly rustic, made with sheet roofs (cardboard or galvanized), wooden fences,

With the facilities

Birth corrals

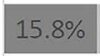

$84.2 \%$

Corrals for sheep sick

$$
2.6 \%
$$
$97.4 \%$

Feedlot corrals

$21 \%$

Handling corrals

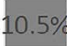
$89.5 \%$

Figure 1. Percentage and type of facilities within the sheep production units at Santa Rita Tlahuapan, Puebla, Mexico.

Table 1. Gender and the average quantity of eggs ( \pm standard error) per gram of sheep feces in the herds of the assessed communities.

\begin{tabular}{l|c|c|c} 
Genus & Average & Minimum & Maximum \\
\hline Trichuris spp & $28.7 \pm 9.0$ & 0 & 200 \\
\hline Eimerias spp. & $472.8 \pm 85.0$ & 10 & 2350 \\
\hline Nematodos spp. & $660 \pm 65.2$ & 50 & 1600 \\
\hline Toxacara spp. & $11.4 \pm 5.8$ & 0 & 150
\end{tabular}

wire, mesh and dirt floors, with feeders and drinkers. The herds are usually kept in a single enclosure pen where animals from different physiological stages coexist, most lack other types of pens (Figure 1), such as pens for sick animals, handling pens, births corrals, or even feedlots.

Health: Most of the producers mentioned that they perceive the health of their herds to be between bad (44.7\%) and fair (39.7\%); only $15.6 \%$ perceive it as good. Although they mentioned these had been treated for parasites, high abundances of internal parasites were detected, mainly Nematodes and Eimeirias genera (Table 1). Brucella was not detected.

Mortality: Mortality is less frequent in adult animals than in lambs under one year of age (Figure 2). The main causes are poor nutrition, the poor conditions of the animal housing areas as they provide poor protection against the weather and the lack of preventive medicine.

Producer's typology: Four groups were identified (Figure 3 and Table 2):

1) Small producers of advanced age: the most prevalent (19 production units, 50\% of the sample), made up of older producers (65 years on average), low schooling (only primary school), little animal inventory (24 sheep on average and an average three from other ruminants) and fewer crops for sheep feeding (two).

2) Young small producers made up of 16 production units (42.1\% of the sample), of younger producers ( 44 years old).

3) Producers with the high sheep number and sales made up of two production units $(5.2 \%$ of the sample). The difference between this group and the previous two is the greater number of sheep in the herds (182 animals' average) and the highest-selling.

4) Producers with forage crops: one production unit (3\% of the sample). The particularity of this unit is that it has the same number of sheep as group 1 and 2; however, in the unit, the producer sows different forage crops (12) to feed their sheep.
Figure 2. Mortality of animals per herd in sheep production units in three communities of Santa Rita Tlahuapan, Puebla. A) In adult animals; B) in lambs less than one-year-old. 


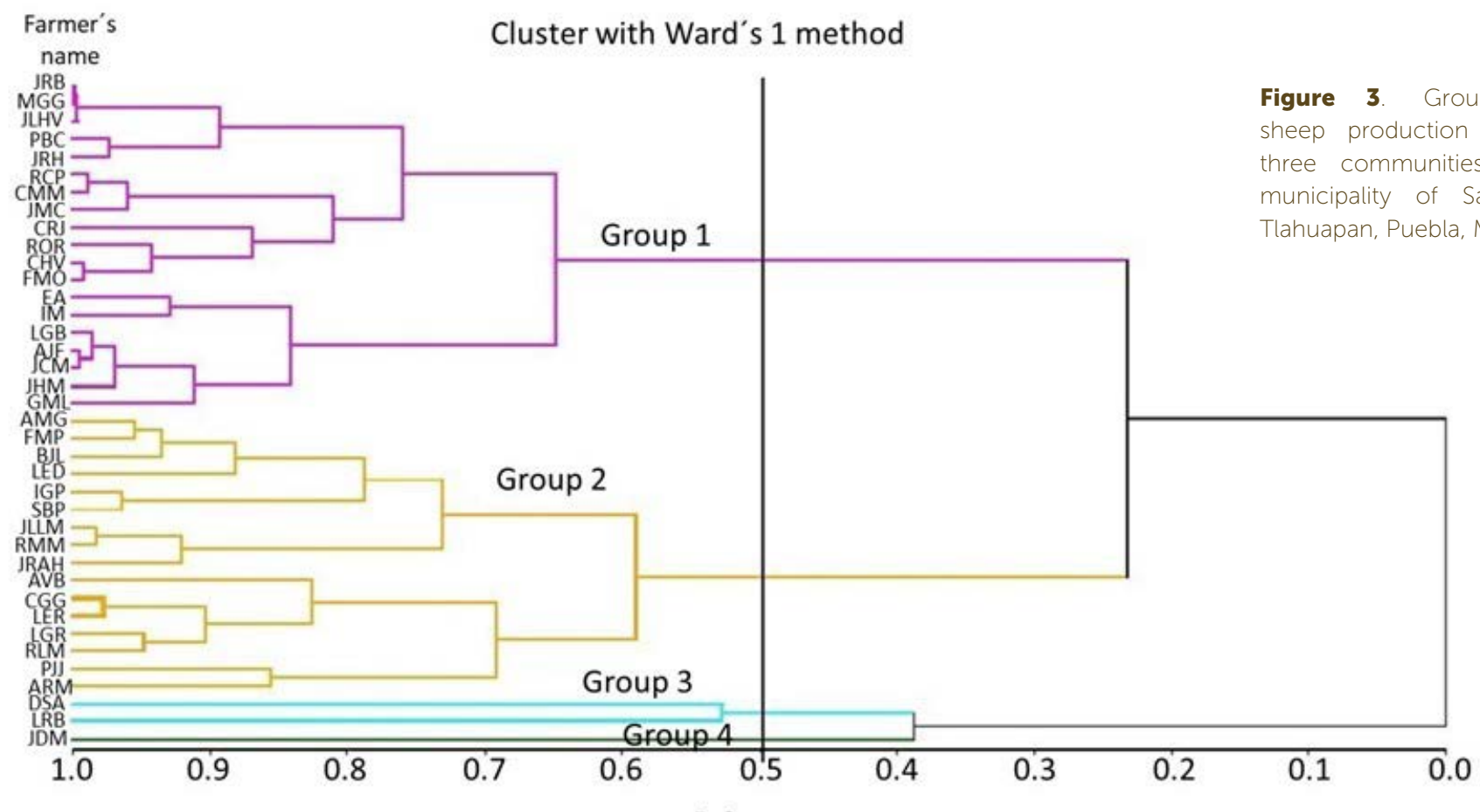

R-Square

\begin{tabular}{|c|c|c|c|c|c|}
\hline \multirow{2}{*}{ Variates } & \multicolumn{4}{|c|}{ Groups } & \multirow{2}{*}{ Average } \\
\hline & 1 & 2 & 3 & 4 & \\
\hline Age & $65 a$ & $44 b$ & $54 a$ & $42 b$ & 55.0 \\
\hline Years of school & $2 b$ & $7 a$ & $8 a$ & $6 a$ & 4.0 \\
\hline Sheep & $24 b$ & $35 b$ & $182 a$ & $36 b$ & 37.0 \\
\hline Other ruminats & $3 b$ & $2 b$ & $\mathrm{Ob}$ & $120 a$ & 6.0 \\
\hline Loss of animals & $3 c$ & $4 c$ & $15 b$ & 22 a & 4.5 \\
\hline Forage crops & $2 b$ & $4 b$ & $3 b$ & $12 \mathrm{a}$ & 2.8 \\
\hline Sales & $4 c$ & $3 c$ & $30 a$ & $15 b$ & 4.8 \\
\hline
\end{tabular}

\section{Characteristics of the production units}

The producer grouping analysis indicated that the majority of the assessed sheep farmers (95\%) are "smallscale", classified within what Gizaw et al. (2010) and Tesfay et al. (2014) call subsistence production systems. These systems are characterized by having few dietary inputs, little infrastructure in the production units and, overall, low livestock productivity, kept as a source of economic savings (Legesse et al., 2008).

Producer's profile: Following the classification by IniestaArandia et al. (2014), the producer's age in the present study is still in productive age. However, at this age (55 years), limitations likely arouse when adopting new management practices and herd augmentation. Morris et al. (2017) discusses that older agricultural producers with low education may have greater limitations to access and adopt new technologies, mainly due to the gaps made by rapid progress, their reduced social network and changes in perspective when entering old age. Likewise, according to Legesse et al. (2008) sheep producers with higher education (9-11 years) tend to improve herd management practices, generate specific production objectives, and seek to improve the profitability of their subsistence sheep farming. Based on this, the older age and the low average schooling (5 years) of the evaluated sheep breeders may be reasons for these production units to be marginalized.

Land tenure and herd size: Similar results regard land tenure are reported by Tilahun et al. (2006) and Kechero et al. (2013), who points out that most of the producers lack their own grazing lands, the available agricultural areas are mainly for basic crops sowing, and there is a reduced area of communal pastures. This helps to explain the low animal number (37 sheep) for each production unit in the current study, factors that, according to Legesse et al. (2008) and Tesfay and Kumar (2014) conditions the herd size increase. Smaller herd sizes (9-11 sheep per unit) than the current investigation are reported by Tilahun et al. (2006); while Hernández et al. (2019) report similar size to that of the current study 
(30-33 sheep), a number linked to the scarcity of own grazing lands.

Housing: Tilahun et al. (2006), Kechero et al. (2013) and Lakew et al. (2017) indicate in their studies that most sheep producers (85-88\%) house their animals in rustic pens, together with other ruminants (goats and cattle); with little or no and few cleanings. According to Kechero et al. (2013), with this, diseases, infections, and parasites (internal and external) of economic importance are increased, a similar situation found in the present study. This may be aggravated by the lack of clinical knowledge of the producers, the low veterinary coverage in the study area, coupled with the price of possibly expensive treatments.

The fact that the herds are not separated by batches, according to Tilahun et al. (2006), Tesfay and Kumar (2014) and Lakew et al. (2017) induces early and uncontrolled reproduction in females, with extreme inbreeding cases, low lamb weights at birth, and low growth rates. In addition to this, the birth season generally occurs during unfavorable times (i.e., during drought or forage shortages) for newborn lambs. In these cases, likely, the females will not reach their maximum colostrum and milk production levels, which in turn, lead to poor lamb nutrition and high lamb mortality (34-57\%) before weaning. The latter could explain the higher mortality of under one year of age lambs compared to adults in the current study.

Feeding: Grazing in degraded rangelands and with low nutritional value forage species and post-harvest crop areas is the main source of food for sheep in several regions of the world. It can contribute in large proportions to sheep feeding in family productive units (Gizaw et al., 2010). However, Legesse et al. (2008) and Gizaw et al. (2010) mention that forage in these sites is seasonal, and when scarce, it has low crude protein and digestibility levels. In this way, by not meeting the nutritional requirements, weight gains and body condition are negatively affected. Therefore, sheep must be supplemented; still, it is only done with sporadic applications of vitamins and mineral salts supply. This was found in the present study and coincides with that reported by Tilahun et al. (2006) where producers supplement the sheep with common salt and some other local minerals from the region, but even so, a good diet is not achieved.

\section{CONCLUSIONS}

Sheep farming in the study area is a subsistence mixed production system (crops-livestock). The main limiting factors, directly from the producers, that can stagnate production are age and schooling, which have certain implications for technological changes. The scarce availability of forages, the nutritional stress of the animals and the deficient sanitation and housing practices are also limiting

\section{REFERENCES}

Alonso, D.M.A., Torres, A. J. F. J., Sandoval, C.C.A. \& Hoste, H. (2010) Tannins in tropical tree fodders fed to small ruminants: A friendly foe? Small Ruminant Research 89:164-179. https://doi. org/10.1016/j.smallrumres.2009.12.040

Gizaw, S., Tegegne, A., Gebremedhin, B., \& Hoekstra, D. (2010). Sheep and goat production and marketing systems in Ethiopia: characteristics and strategies for improvement. IPMS (Improving Productivity and Market Success) of Etiopian Farmers Project Working. International Livestock Institute. 58 pp. https://doi. org/10.1016/j.livsci.2009.10.016

Hernández, V.D., Sánchez, V.E., Gómez, D.W., \& Martínez, G.C.G. (2019). Caracterización productiva y socioeconómica del sistema de producción ovina, en un área natural protegida de México. Revista Mexicana de Ciencias Pecuarias, 10(4): $951-$ 965. https://dx.doi.org/10.22319/rmcp.v10i4.4470

Iniesta-Arandia, I., Del Amo, D.G., García-Nieto, A.P., Piñeiro, C., Montes, C., \& Martín-López, B. (2014). Factors influencing local ecological knowledge maintenance in Mediterranean watersheds: Insights for environmental policies. Ambio 44:285296. https://doi.org/10.1007/s13280-014-0556-1

Kechero, Y., Taye, T., \& Aynalem, H. (2013). Characteristics and determinants of livestock production in Jimma Zone/ Southwestern Ethiopia. African Journal of Basic and Applied Sciences 5:69-81. https://doi.org/10.5829/idosi. ajbas.2013.5.2.314

Köbrich, C., Rehman, T. \& Khan, M. (2010). Typification of farming systems for constructing representative farm models: two illustrations of the application of multi-variate analyses in Chile and Pakistan. Agricultural Systems 76:141-157. https://doi. org/10.1016/S0308-521X(02)00013-6

Lakew, A., Aberra, M. \& Sandip, B. (2017). Traditional sheep production systems and breeding practice in Wolayita Zone of Southerm Ethiopia. African Journal of Agricultural Research 12:1689-1701. https://doi.org/10.5897/AJAR2016.11940

Legesse, G., Abebe, G., Siegmundo-Schultze, M., \& Valle, Z.A. (2008). Small ruminant production in two mexied-farming systems of southern Ethiopia: status and prospects for improvement. Experimental Agriculture 44:399-412. https://doi.org/10.1017/ S0014479708006376

Morris, W., Henley, A., \& Dowel, D. (2017). Farm diversification, entrepreneurship and technology adoption: analysis of upland farmers in Wales. Journal of Rural Studies 53: 132-143. https:// doi.org/10.1016/j.jrurstud.2017.05.014

Norma Oficial Mexicana NOM-041-ZOO-1995. Campaña Nacional contra la Brucelosis en los animales. Disponible en: http:// 
www.senasica.gob.mx/?doc $=506$. Consultado el 28 de diciembre de 2017

Olayiwola, O.M., Apantaku, F.S., Bisira, H.O., \& Adewara, A.A. (2013) Efficiency of Neyman Allocation procedure over other allocation procedures in stratified random sampling. American Journal of Theoretical and Applied Statistics 2(5): 122-127. https://doi.or/10.11648/j.ajtas.20130205.12

SAS Institute Inc. (2002). SAS Software version 9.0. SAS Institute, Inc Cary, NC, USA.

Tesfay, G.Z., \& Kumar, A.A. (2014). Indigenous sheep breeds of North Ethiopia: characterization of their phenotype and major production system. Tropical Animal Health and Production 46:341-347. https://doi.org/10.1007/s11250-013-0494-0

Tilahun, S., Pravee, V., Pornsri, C., \& Suwapong, S. (2006). Assessment of small ruminant management practices in Jijiga and Shinile Zones of Somali Regional State, Ethiopia. Kasetsart Journal (Natural Science) 40:987-999.

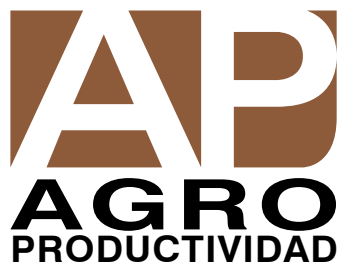

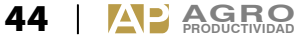

